Review Article

\title{
Insights into the Role of Circadian Rhythms in Bone Metabolism: A Promising Intervention Target?
}

\author{
Chao Song, ${ }^{1}$ Jia Wang, ${ }^{1}$ Brett Kim, ${ }^{2}$ Chanyi Lu, ${ }^{2}$ Zheng Zhang, ${ }^{1}$ Huiyong Liu, \\ Honglei Kang, ${ }^{1}$ Yunlong Sun, ${ }^{1}$ Hanfeng Guan, ${ }^{1}$ Zhong Fang $\mathbb{C},{ }^{1,3}$ and Feng $\mathrm{Li} \mathbb{C}^{1,3}$ \\ ${ }^{1}$ Department of Orthopaedic Surgery, Tongji Hospital, Tongji Medical College, \\ Huazhong University of Science and Technology, Wuhan, China \\ ${ }^{2}$ Department of Periodontics, School of Dental Medicine, University of Pennsylvania, Philadelphia, PA, USA \\ ${ }^{3}$ Biological Engineering and Regenerative Medicine Center, Tongji Hospital, Tongji Medical College, \\ Huazhong University of Science and Technology, Wuhan, China \\ Correspondence should be addressed to Zhong Fang; zhongfangtjh@yahoo.com and Feng Li; lifengmd@hust.edu.cn
}

Received 28 June 2018; Accepted 9 September 2018; Published 27 September 2018

Academic Editor: Giuseppe Piccione

Copyright (C) 2018 Chao Song et al. This is an open access article distributed under the Creative Commons Attribution License, which permits unrestricted use, distribution, and reproduction in any medium, provided the original work is properly cited.

\begin{abstract}
Numerous physiological processes of mammals, including bone metabolism, are regulated by the circadian clock system, which consists of a central regulator, the suprachiasmatic nucleus (SCN), and the peripheral oscillators of the BMAL1/CLOCK-PERs/CRYs system. Various bone turnover markers and bone metabolism-regulating hormones such as melatonin and parathyroid hormone (PTH) display diurnal rhythmicity. According to previous research, disruption of the circadian clock due to shift work, sleep restriction, or clock gene knockout is associated with osteoporosis or other abnormal bone metabolism, showing the importance of the circadian clock system for maintaining homeostasis of bone metabolism. Moreover, common causes of osteoporosis, including postmenopausal status and aging, are associated with changes in the circadian clock. In our previous research, we found that agonism of the circadian regulators REV-ERBs inhibits osteoclast differentiation and ameliorates ovariectomy-induced bone loss in mice, suggesting that clock genes may be promising intervention targets for abnormal bone metabolism. Moreover, osteoporosis interventions at different time points can provide varying degrees of bone protection, showing the importance of accounting for circadian rhythms for optimal curative effects in clinical treatment of osteoporosis. In this review, we summarize current knowledge about circadian rhythms and bone metabolism.
\end{abstract}

\section{Introduction}

Mammals have developed endogenous circadian clocks in response to Earth's rotation, characterized by approximately 24 -hour cycles. Circadian clocks are maintained by a central regulator, the suprachiasmatic nucleus (SCN), located in the hypothalamus, as well as a peripheral circadian clock system consisting of BMAL1/CLOCK, PERs/CRYs, REVERBs/RORs, DECs, and DBP (molecular oscillators). Lesions on the SCN led to disrupted circadian rhythms in terms of temperature, sleep, and locomotor activity, and SCN transplantation restored circadian rhythms in SCN-ablated animals $[1,2]$. Similar abnormal circadian rhythms were also observed in clock gene knockout mice [3].
As the master oscillator, SCN organizes the clocks in peripheral tissues through sympathetic pathways and release of glucocorticoids. Heart rate and plasma glucose content are regulated by $\mathrm{SCN}$ via the sympathetic nervous system $[4,5]$. Moreover, glucocorticoids modulated by the master pacemaker synchronize peripheral circadian rhythms, acting as signals [6,7]. Entrainment factors such as light and food synchronize the master circadian clock in the SCN. Light information reaches the SCN via the retina and the retinal-hypothalamic tract and serves as the most potent synchronizer. In contrast, food has a much less synchronizing influence on the SCN, with the exception of foods with high palatability $[8,9]$. 


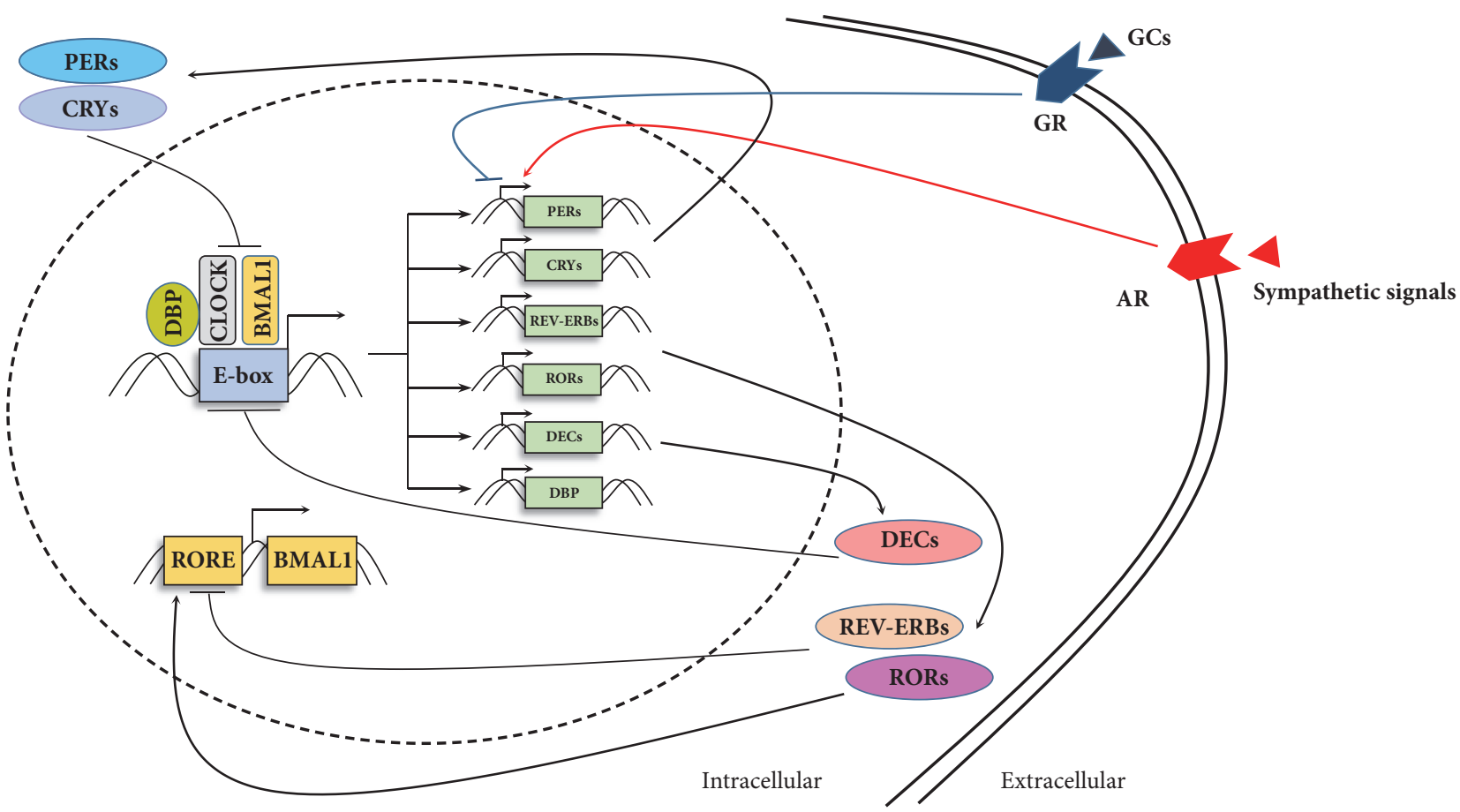

FIGURE 1: Molecular clock machinery. The feedback loop of clock genes and proteins is comprised of 2 main branches: CLOCK/BMAL1PERs/CRYs and the supplementary regulators REV-ERBs, RORs, DECs and DBP. Glucocorticoids and sympathetic signals regulate circadian oscillators by modulating transactivation of PER1. CLOCK, circadian locomotor output cycles kaput; BMAL1, brain and muscle ARNT-like 1; PER, period circadian clock; CRY, cryptochrome; DBP, D-site binding protein; RORs, retinoid-related orphan receptors; RORE, ROR response element; DEC, differentiated embryo-chondrocyte expressed gene; GC, glucocorticoid; GR, glucocorticoid receptor; AR, adrenergic receptor.

In peripheral tissues, cellular circadian rhythms are maintained by molecular oscillators including BMAL1/CLOCK, PERs/CRYs, REV-ERBs/RORs, DECs and DBP. A complex including "circadian locomotor output cycles kaput" (CLOCK) and "brain and muscle ARNT-like 1" (BMAL1) drives transcription of target genes by binding to E-box elements in promoters, including those of periods (PER1, PER2, and PER3), cryptochromes (CRY1 and CRY2), reverse orientation c-erb $\alpha(\mathrm{REV}-\mathrm{ERB} \alpha)$ and RAR-related orphan receptor $\alpha(\operatorname{ROR} \alpha)$. Heterodimers of PERs and CRYs, in turn, repress the transcriptional activities of BMAL1 and CLOCK [10]. Moreover, REV-ERB $\alpha$ suppresses transcription of BMAL1, whereas ROR $\alpha$ enhances it [11]. DEC1 and DEC2 repressed CLOCK/BMAL1-induced transactivation of the PER1 promoter by interacting with BMAL1 and competing for E-box elements [12]. BMAL1/CLOCK drives circadian transcription of DBP, which activates transcription of PER1 in conjunction with BMAL1/CLOCK $[13,14]$ (Figure 1).

Aging and postmenopausal status are the most common causes of primary osteoporosis. Ovariectomy attenuates oscillation of circadian clock genes in murine bones, including CLOCK, BMAL1, CRY2 and REV-ERB $\alpha$ [15]. Although aged mice exhibit normal oscillation amplitudes, peripheral clock responses to exercise and stress stimuli were impaired [16].

Our previous research found that REV-ERBs agonism suppressed RANKL-induced (receptor activator of nuclear factor kappa-B ligand) osteoclast differentiation and ameliorated ovariectomy-induced bone loss [17]. In this review, we give an overview of correlations between bone metabolism and circadian rhythms in 6 parts: (1) circadian rhythms of bone metabolism; (2) impacts of circadian disruption on bone metabolism; (3) output signals of SCN regulate bone metabolism: sympathetic nervous signals and glucocorticoids; (4) hormones link circadian rhythms with bone metabolism; (5) Peripheral oscillators in bone; (6) implications of circadian rhythms in interventions for bone metabolism disorders.

\section{Circadian Rhythm of Bone Metabolism}

Bone metabolism exhibits daily patterns, represented by circadian rhythmicity, of bone turnover markers. In a study including 10 healthy men, the bone resorption marker Cterminal cross-linked telopeptide of type I collagen (CTX) displayed a diurnal rhythm, peaking at 05:30 (range 01:30 - 07:30) [18], which was consistent with previous studies $[19,20]$. FGF23, a component of osteocyte function, also showed rhythmicity [21]. Similar rhythmicity was not found in sclerostin. Further, no rhythmic variations were observed in osteoprotegerin (OPG) or soluble RANKL (sRANKL) serum levels with a diurnal cycle $[22,23]$. Paradoxically, another study showed that OPG displayed a circadian rhythm of a daytime increase and nocturnal decrease [24].

In dromedary camels, osteocalcin reaches its minimum and maximum concentrations of the $24-\mathrm{h}$ period at $1300 \mathrm{~h}$ 
and at $1800 \mathrm{~h}$, respectively [25]. In Gambian, Chinese, and white British adults, levels of plasma CTX, procollagen type 1 $\mathrm{N}$-propeptide (P1NP), $\mathrm{N}$-mid osteocalcin and bone alkaline phosphatase all show rhythmic patterns [26]. Intriguingly, the circadian rhythm of the CTX level can be broken by fasting but not by nasal administration of salmon calcitonin [19].

Using noninvasive Raman microscopy, McElderry et al. found that mineral deposition in calvarial tissue exhibits rhythmicity with a periodicity of $26.8 \pm 9.6$ hours, with the earliest mineralization events occurring 6 hours after PER1 expression [27]. Similarly, the concentrations of calcium and inorganic phosphorus in rat metaphyseal bones displayed apparent circadian rhythms with peaks during dark periods [28].

In transgenic mice harboring the human osteocalcin promoter linked to a luciferase reporter gene, the maxillomandibular complex, calvaria, tail, carpals, and tarsals all displayed oscillatory patterns of osteogenic activity [29]. Moreover, Zvonic et al. showed that both elements of the circadian transcriptional apparatus (BMAL1/CLOCK/CRYs/PERs) and their mediators (DBP and REV-ERBs) exhibited oscillatory expression profiles in murine calvarial bones [30]. Russell et al. found that bone collagen formation also showed circadian fluctuations. Specifically, during assembly in dark periods, secretion of bone collagenous protein was decreased, as compared to light periods [31].

\section{Impact of Circadian Disruption on Bone Metabolism}

Sleep and eating are regulated by the circadian clock and can entrain circadian rhythms [32, 33]. Shift work, sleep restriction and fasting are common situations that may lead to circadian misalignments.

Shift workers are reported to have lower bone mineral density (BMD) and increased fracture risk compared to daytime workers [34,35]. Deficit of 25-OH vitamin D3 caused by decreased open-air exposure may be responsible for this phenomenon [36]. In postmenopausal women, inadequate nocturnal sleep was associated with greater risk of bone loss [37]. Moreover, Swanson et al. reported that 3 weeks of circadian disruption with concurrent sleep restriction led to decreased P1NP and unchanged CTX [38]. A prospective cohort study demonstrated that the overall circadian rhythmicity of rest and activity (pseudo F-statistic) and daytime to nighttime activity ratio (alpha statistic) are associated with areal BMD (aBMD) of the total hip and femoral neck in older men [39]. Intriguingly, exposure to continuous light for 24 weeks is associated with 70\% less rhythmicity of the SCN and with early osteoporosis in mice [40].

Eating times can alter the circadian rhythms of DNA synthesis and collagen synthesis in rat tibia [41]. Moreover, food administration leads to a peak of bone resorption. Dividing food into smaller portions blunted this effect and decreased bone resorption in thyroparathyroidectomized animals [42]. Urinary CrossLaps corrected with creatinine (U-CL/Cr), a bone resorption marker, exhibited a significant circadian rhythm, and its fluctuation was dampened by fasting [43].

\section{Output Signals of SCN Regulate Bone Metabolism}

Circadian signals are transmitted from the central pacemaker SCN to peripheral tissues through the sympathetic nervous system and glucocorticoids $[7,44,45]$ (Figure 2). In vivo administration of adrenaline or noradrenaline increased expression of PER1 in the murine liver. Daily injection of adrenaline recovered oscillation of PER1 and PER2 expression in the livers of mice with disrupted SCNs [46]. Glucocorticoids (cortisol in primates and corticosterone in rodents) secreted by adrenocortical steroidogenic cells exhibit circadian rhythms and are involved in regulation of lipid metabolism, glucose homeostasis and cardiovascular tone [47]. SCN lesions in rats altered synchronization of the adrenal corticosterone rhythm [48]. After glucocorticoids bind to glucocorticoid receptors (GRs), these GRs regulate PER1 directly, rather than through PER2 expression, by binding to a glucocorticoid-responsive element [49].

4.1. Sympathetic Nervous Functions. Treatment with $\beta$ adrenergic receptor agonist (isoprenaline, Iso) or a synthetic glucocorticoid (dexamethasone) immediately induces human osteoblast SaM-1 cells to express hPER1 and hPER2 and causes circadian oscillation of these two genes, with three peaks observed within $48 \mathrm{~h}$ [50]. Moreover, Iso induces rhythmic expression of the osteoblast-related gene Collal. In MC3T3-E1 osteoblastic cells, Iso caused oscillations of PER2 expression [51]. Exposure to phenylephrine (PHE), a nonspecific $\alpha 1$-adrenoreceptor (AR) agonist, induced rhythmic expression of bone morphogenetic protein 4 (BMP4) in MC3T3-E1 cells [52], which promotes osteoblast differentiation [53]. Systemic administration of prazosin, a nonspecific $\alpha 1-\mathrm{AR}$ antagonist, led to decreased bone formation [54]. In addition, $\alpha 1 \beta$-AR-deficient mice exhibited a lower bone mass compared with wild-type mice [54].

FGF23 is an important cytokine that regulates phosphate and vitamin D metabolism. Iso induced FGF23 expression in the femur, but this was not observed in BMAL1 knockout mice [21].

4.2. Glucocorticoids. SCN orchestrates the daily rhythms of circulating glucocorticoids in 2 ways: (1) regulating the hypothalamic-pituitary-adrenal (HPA) axis through efferent projection to paraventricular nucleus (PVN) [55]; (2) inducing gene expression in the adrenal gland via the sympathetic nervous system [45]. Both PER1 deficient PER1 ${ }^{\text {Brd }}$ mice and PER2-/- mice exhibit impaired circadian rhythmicity of circulating glucocorticoids [56, 57]. Glucocorticoids further regulate expression of molecular oscillators through binding to glucocorticoid receptor (GR) in peripheral organs, including heart, liver and kidney [7]. Moreover, Wu X et al. revealed that treatment of murine and human bone marrow mesenchymal stem cells (MSC) with dexamethasone (a synthetic glucocorticoid) synchronizes rhythmic expression of BMAL1, PER3, REV-ERB $\alpha$ and REV-ERB $\beta$ [58]. CLOCK/BMAL1 in turn interact with GR and suppress GRinduced transcriptional activity [59]. 


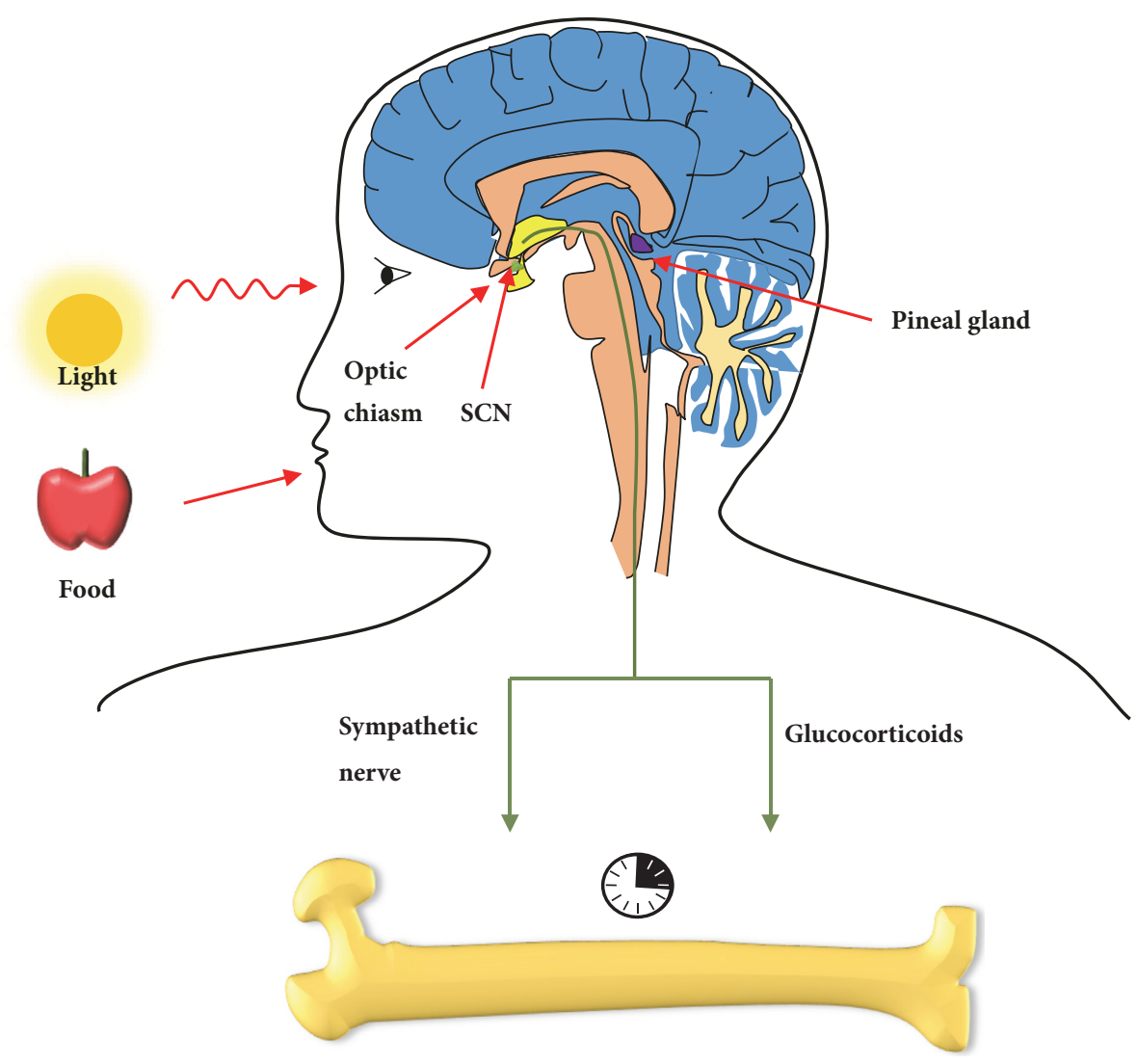

FIGURE 2: Role of the central pacemaker in bone metabolism. Light (major entrainment factor) and food signals entrain circadian rhythms in SCN, which transmits circadian signals to bones through hormones and sympathetic nervous functions.

The impact of glucocorticoids on bone metabolism has been comprehensively investigated in the past decades. Physiological glucocorticoids signaling in osteoblast progenitors is essential for maintaining the normal bone density, whereas endogenous glucocorticoid excess and high dose therapeutic glucocorticoids result in osteoporosis by suppressing osteoblast activity and bone formation $[55,60]$. In vitro study demonstrated that a glucocorticoid rather than a $\beta$-agonist synchronized circadian expression of clock and osteoclastrelated genes in osteoclasts [61]. Moreover, dexamethasone injection recovered circadian expression of cathepsin $\mathrm{K}$ (CTSK) and nuclear factor of activated T-cells, cytoplasmic 1 (NFATc1), in adrenalectomized mice [61].

\section{Hormones Link Circadian Rhythms with Bone Metabolism}

Aside from sympathetic and glucocorticoid signaling, hormones such as melatonin, ghrelin and parathyroid hormone (PTH) can also coordinate circadian rhythms in bone tissue.

5.1. Melatonin. Melatonin is a hormone that regulates sleep and other circadian activities [62]. The SCN regulates melatonin secretion through an inhibitory projection to the paraventricular nucleus, which controls sympathetic output to the pineal gland [63]. Several animal studies have demonstrated that melatonin has beneficial effects on bone metabolism, promoting osteoblast differentiation and suppressing osteoclast formation through oxidative stress reduction and PPAR $\gamma$ suppression [64-66]. On the other hand, nocturnal melatonin administration did not improve bone parameters in a blind model using MMTV-Neu transgenic mice [67]. Moreover, a double-blind clinical study demonstrated that there was no difference in bone density, osteocalcin, or NTX between nightly melatonin supplementation and placebo groups [68].

5.2. Ghrelin. Levels of the orexigenic peptide ghrelin exhibit circadian rhythms, and this hormone has been found to induce a phase advance of circadian time in the SCN of about $3 \mathrm{~h}$ in vitro [69], causing expression of ghrelin receptor (GHSR). GHSR knockout mice displayed lengthening of their circadian period and greater activity in anticipation of a scheduled meal under constant lighting conditions [70]. In terms of bone metabolism, ghrelin has been shown to promote proliferation and prevent apoptosis of osteoblasts. However, clinical studies of serum ghrelin and BMD demonstrated no correlation between them $[71,72]$.

5.3. PTH. PTH exhibits a moderate increase between 16:00 and 19:00 and a broader, longer-lasting increase from late evening to early morning, reaching its peak between 02:00 
TABLE 1: Summary of circadian and bone phenotypes in clock gene transgenic mice.

\begin{tabular}{|c|c|c|}
\hline Gene & Circadian phenotype & Bone phenotype \\
\hline CLOCK & $\begin{array}{l}\text { CLOCK mutant mice }\left(\text { Clock }^{\Delta 19 / \Delta 19}\right) \text { : long circadian } \\
\text { period }(26-28 \mathrm{~h})[80] \\
\text { CLOCK knockout mice: robust circadian rhythm in } \\
\text { locomotor activity [81] }\end{array}$ & Clock mutant mice: low bone mass [83] \\
\hline BMAL1 & BMAL1-/- mice: impaired locomotor activity [87] & BMAL1 knockout mice: low bone mass [87] \\
\hline PERs & $\begin{array}{l}\text { PER1-deficient mice: disrupted circadian behavioral } \\
\text { rhythms [89] } \\
\text { PER2-deficient mice: disrupted circadian behavioral } \\
\text { rhythms [89] }\end{array}$ & $\begin{array}{c}\text { PER1-deficient mice: normal bone volume [91] } \\
\text { PER2-deficient mice: normal bone volume [91] } \\
\text { PER2 PAS domain }\left(\text { PER2 }{ }^{\mathrm{m} / \mathrm{m}}\right) \text { : normal bone volume } \\
{[91]} \\
\text { PER1 }^{-/-} ; \text {PER2 }{ }^{\mathrm{m} / \mathrm{m}} \text { : significantly increased bone mass } \\
{[91]} \\
\text { PER1-/-; PER2-/-: increased bone mass [91] } \\
\text { Per2 }{ }^{\text {Brdm1 }} \text { mice: increased bone volume at } 3,12 \text { and } 48 \\
\text { weeks [92] }\end{array}$ \\
\hline CRYs & $\begin{array}{c}\text { CRY1-deficient mice: circadian period } 1 \text { hour shorter } \\
\text { than wild type }[93,94] \\
\text { CRY2-deficient mice: circadian period } 1 \text { hour longer } \\
\text { than wild type [95] } \\
\text { CRY1/2 double knockout mice: arrhythmic in constant } \\
\text { darkness [121] }\end{array}$ & $\begin{array}{l}\text { CRY1-deficient mice: not reported } \\
\text { CRY2-deficient mice: increased bone volume [94] } \\
\text { CRY1/2 double knockout mice: high bone volume [91] }\end{array}$ \\
\hline REV-ERBs & $\begin{array}{c}\text { REV-ERB } \alpha \text { knockout: average period length } \\
\text { significantly shorter [122] } \\
\text { REV-ERB } \beta \text { knockout: no changes in circadian activity } \\
\text { rhythms [123] } \\
\text { REV-ERB } \alpha / \beta \text { double knockout: the free running period } \\
\text { length in constant darkness was } 2.5 \text { hours shorter [123] }\end{array}$ & $\begin{array}{l}\text { REV-ERB } \alpha \text { knockout: not reported } \\
\text { REV-ERB } \beta \text { knockout: not reported } \\
\text { REV-ERB } \alpha / \beta \text { agonist SR9009: suppressed osteoclast } \\
\text { formation and ameliorated OVX-induced bone loss [17] }\end{array}$ \\
\hline RORs & $\begin{array}{l}\text { ROR } \alpha \text { (sg/sg): shortened period length of the } \\
\text { locomotor activity rhythm [102] } \\
\text { ROR } \beta \text { knockout: significant increase in circadian } \\
\text { period in constant dark [103] }\end{array}$ & $\begin{array}{c}\operatorname{ROR} \alpha(s g / s g) \text { : osteopenic [104] } \\
\text { ROR } \beta \text { knockout: increase bone mass [108] }\end{array}$ \\
\hline DECs & $\begin{array}{c}\text { DEC1 knockout: longer circadian period under } \\
\text { conditions of constant darkness [109] } \\
\text { DEC2 knockout: no changes in circadian activity } \\
\text { rhythms [110] }\end{array}$ & DEC1 or DEC2 knockout: not reported \\
\hline DBP & DBP knockout: shorter period [124] & DBP knockout: normal bone volume [120] \\
\hline
\end{tabular}

and 06:00 [26, 73]. The direct connection between SCN and PTH secretion remains uncharacterized.

Constitutively active PTH receptors expressed in osteoblasts promote PER1 expression [74]. In organ-cultured murine femur, Okubo et al. revealed that PTH reset the circadian oscillation of PER2::luciferase activity in a timeand dose-dependent manner [75]. Moreover, PTH administration shifts the peak time of PER2::luciferase activity in fracture sites and growth plates [76]

\section{Peripheral Oscillators in Bone}

Circadian rhythms in peripheral tissues are governed by an autoregulatory transcriptional and translational feedback loop with two branches: the positive transcriptional branch comprised of CLOCK and BMAL1 and the negative branch formed by PERs and CRYs. Circadian regulation genes including REV-ERBs, RORs, DECs and DBP play vital roles in the circadian system. Among these genes, BMAL1 (ARNTL), DBP, NR1D1 (REV-ERB $\alpha$ ), NR1D2 (REV-ERB $\beta)$,
PER1, PER2, and PER3 have been observed to oscillate in all mammalian organs, including the $\operatorname{SCN}[77,78]$. In human mesenchymal stem cells, expression of the circadian genes CLOCK, BMAL1, PER1, and PER2 displayed rhythmicity [79]. These clock genes play complex roles in bone metabolism (Table 1).

6.1. CLOCK. Homozygous CLOCK mutant mice $\left(C l o c k^{\triangle 19 / \triangle 19}\right)$ were reported to display lengthened circadian periods (26-28h in length) [80]. On the other hand, Debruyne et al. reported that CLOCK knockout mice showed robust circadian rhythms in locomotor activity [81]. Subsequent research from the same group demonstrated that NPAS2 functionally substitutes for CLOCK in SCN [82]. In terms of bone metabolism, CLOCK mutant mice exhibit decreased bone density due to reduced expression of Pdia3, a 1, 25-dihydroxy-vitamin D3 receptor [83]. Pdia3 deficiency resulted in reduced relative bone volume (BV/TV) and trabecular number [84]. 
6.2. BMAL1. Mice deficient in BMAL1 displayed impaired locomotor activity during light-dark (LD) cycles as well as various symptoms of premature aging, including sarcopenia, cataracts, reduced subcutaneous fat and organ shrinkage $[85,86]$. Deletion of Bmall results in low bone mass [87]. Conditional deletion of Bmall in osteoblasts led to reduced bone loss and increased bone resorption. Subsequent coculturing revealed that Bmall-deficient osteoblasts promote osteoclastogenesis [88].

6.3. PERs. Both PER1- and PER2-deficient mice showed severely disrupted locomotor activity rhythms [89]. Lightinduced expression of PER1 and PER2 proteins in the SCN is essential for entrainment [90].

According to Fu et al., mice lacking PER1, PER2 or the PER2 PAS domain $\left(P E R 2^{\mathrm{m} / \mathrm{m}}\right.$ ) exhibit normal bone volume, whereas $\mathrm{PER}^{-/-} ; \mathrm{PER}^{-/-}$and $\mathrm{PER}^{-/-} ; \mathrm{PER}^{\mathrm{m} / \mathrm{m}}$ mice display increased bone mass. Leptin intracerebroventricular infusion further increases bone mass of PER1 ${ }^{-/-}$; PER2 ${ }^{\mathrm{m} / \mathrm{m}}$ mice [91].

In contrast, Maronde et al. reported that PER2-mutant PER2 ${ }^{\mathrm{Brdm} 1}$ mice displayed greater bone volumes compared with wild-type mice [92].

6.4. CRYs. The circadian period is 1 hour shorter in CRY1 knockout mice, whereas it is 1 hour longer in CRY2 knockout mice [93-95]. CRY2-deficient mice display increased bone volume with low osteoclast activity [94]. Moreover, mice lacking CRY1 and CRY2 exhibit increased bone volume [91]. In a Chinese pediatric cohort, Cry2 rs2292910 was associated with osteoporosis $(\mathrm{r}=-0.082, \mathrm{p}=0.045)$ [96].

6.5. $R E V-E R B s$. REV-ERB $\alpha$ and REV-ERB $\beta$ were found to regulate hepatic lipid metabolism and skeletal muscle activity in addition to their roles in the cell autonomous clock [97, 98].

Our previous work demonstrated that REV-ERB agonism of SR9009 suppresses osteoclast formation and ameliorates ovariectomy-induced bone loss [17]. REV-ERB $\alpha$ was significantly increased in bone mesenchymal stem cells of old rhesus monkeys, which were characterized by decreased osteogenetic capacity and significantly increased REV-ERB $\alpha$ expression [99]. Furthermore, overexpression of REV-ERB $\alpha$ in bone mesenchymal stem cells inhibited osteogenesis [100].

6.6. RORs. RORs regulate target gene expression by binding to ROR response elements (RORE) containing the RGGTCA consensus motif [101]. ROR $\alpha$ (sg/sg) mice displayed a shortened period of the locomotor activity rhythm, while ROR $\beta$ knockout mice showed a lengthened circadian period in constant dark [102, 103].

$\operatorname{ROR} \alpha$ (sg/sg) mice with a deletion within the ROR $\alpha$ gene are osteopenic compared with wild-type and heterozygote littermates [104], indicating the essential role of $\operatorname{ROR} \alpha$ in regulation of normal bone metabolism. Further investigation demonstrates that $\operatorname{ROR} \alpha$ directly activates bone sialoprotein expression, which promotes osteoblast differentiation and matrix mineralization [105].

Expression of $\operatorname{ROR} \beta$ is increased in bone marrow precursor cells of aged mice and bone biopsies from postmenopausal women [106]. Overexpression of $\operatorname{ROR} \beta$ in MC3T3-E1 cells results in decreased bone nodule formation [107]. Knockout of the $\operatorname{ROR} \beta$ gene in osteoblasts promotes expression of osteogenic genes and osteoprotegerin (OPG). Consistent with in vitro results, $\mathrm{ROR} \beta-/$ - mice exhibited increased bone volume [108].

6.7. DECs. DEC1 overexpression extended the periods of clock genes such as DEC1, DEC2 and PER1 [109]. Longer circadian periods under conditions of constant darkness were observed in DEC1 knockout mice [109]. However, DEC2 knockout mice showed no changes in their circadian activity rhythms [110].

After osteogenic induction of MSC in medium containing dexamethasone, beta-glycerophosphate, and ascorbic acid, $\mathrm{DEC1}$ expression gradually increased from day 5 to day 14 [111]. Overexpression of DEC1 in growth plate chondrocytes at the prehypertrophic stage increased mRNA levels of Indian hedgehog, Runx2, and type X collagen, and also promoted alkaline phosphatase activity and mineralization [112].

6.8. DBP. DBP, also known as group-specific component (GC), is a polymorphic protein that binds $85-90 \%$ of the total circulating $25-\mathrm{OH}$ vitamin $\mathrm{D}$, which is later transported to the kidneys [113]. In the kidneys, $25-\mathrm{OH}$ vitamin $\mathrm{D}$ is converted to the active form of vitamin $\mathrm{D}, 1,25$-dihydroxyvitamin $\mathrm{D}\left(1,25(\mathrm{OH})_{2} \mathrm{D}\right)$. DBP can also be converted to DBPmacrophage activating factor (DBP-MAF), which directly promotes osteoclast formation [114]. DBP protein and mRNA in the SCN and various peripheral tissues display strong circadian rhythmicity [115]. DBP activates transcription of PER1 in cooperation with CLOCK/BMAL1, which regulate the circadian transcription of DBP through interaction with E boxes [14].

Genotyping based on rs4588 of the GC gene showed that total hip-bone mineral content was associated with GC genotype $(p=0.05, A N C O V A)$ in boys [116]. In women of postmenopausal age, $\mathrm{DBP} * 10$ (with 10 repeats of TAAA) is associated with lower incidence of bone fracture compared with relevant controls, while $\mathrm{DBP} * 11$ is related to higher incidence [117]. Another study showed that DBP $* 10$ and $\mathrm{DBP} * 11$ are both associated with lower risks of osteoporosis [118]. A highly suggestive association was found between DBP SNPs (single nucleotide polymorphisms) and spine BMD [119].

Despite associations between DBP genotype and BMD, DBP-deficient mice displayed normal bone volume [120].

\section{Implications of Circadian Rhythms in Interventions for Bone Metabolism Disorders}

Salmon calcitonin (sCT) is a widely used antiosteoporosis drug. Karsdal et al. assessed CTX-I levels after oral salmon 
calcitonin intake at three different time points (morning, predinner and evening) in healthy postmenopausal women and found that pre-dinner dosing of oral sCT resulted in optimal efficacy of CTX-I downregulation [125].

PTH is the only FDA approved anabolic drug for osteoporosis. A 12-month clinical investigation demonstrated that morning administration of teriparatide resulted in higher spine BMD compared to evening application [126].

Pulsed electromagnetic fields (PEMF) have been reported as an effective method of preventing osteoporosis, and daytime PEMF application from 9:00 to 15:00 was more effective for prevention of ovariectomy-induced bone loss than nighttime PEMF from 0:00 to 6:00 [127].

Together, these results indicate that circadian rhythms should be considered when treating bone disorders.

\section{Conclusions}

Bones are organs under dynamic regulation of osteoblasts, osteoclasts, osteocytes, and bone lining cells. Disruption of the balance between these cells leads to diseases such as osteoporosis. The prevalence of osteoporosis and low bone mass is estimated at $10.3 \%$ and $43.9 \%$ among US adults aged 50 and older, respectively [128]. According to a 2002 national population sample, the annual cost of osteoporosis and fractures in elderly patients in the US was up to \$16 billion [129].

Circadian rhythms are regulated by the central oscillator SCN and the peripheral clock system, which contribute to maintaining homeostasis of physiological functions. Circadian arrhythmia is related to disorders such as neurodegenerative diseases [130], metabolic syndrome, cancer [131], and cardiovascular disease [132]. Increasing evidence demonstrates that the circadian clock systems, including the master pacemaker and peripheral circadian machinery, play pivotal roles in maintaining homeostasis of bone metabolism. Circadian disruption due to sleep restriction, shift work, fasting, or knockout of clock genes results in disrupted homeostasis of bone metabolism.

Among the various molecular oscillators, REV-ERBs and RORs are nuclear receptors that can be activated by their natural ligands, heme, and oxygenated sterols, respectively [133]. Various synthetic ligands with high affinities for REV-ERBs and RORs have been developed based on their structures. These ligands display promising therapeutic effects in animal studies, including those on tumors [134], type 1 diabetes [135], atherosclerosis [136], and autism [137]. Combining these studies with our previous findings [17], REV-ERBs and RORs appear to offer promising therapy targets for several disorders, including osteoporosis [138].

In this review, we provide insight into the role of circadian rhythms in bone metabolism, and show evidence that the circadian system may be a promising target of clinical intervention for abnormal bone metabolism.

\section{Conflicts of Interest}

The authors declare no conflicts of interest.

\section{Authors' Contributions}

Chao Song, Feng Li, and Zhong Fang searched literatures, collected data, and prepared the initial manuscript. All coauthors took part in revision of the review.

\section{Acknowledgments}

This research was supported by grants from the National Key Research and Development Program of China (no. 2016YFB1101305) and National Nature Science Foundation of China (no. 81472133).

\section{References}

[1] C. I. Eastman, R. E. Mistlberger, and A. Rechtschaffen, "Suprachiasmatic nuclei lesions eliminate circadian temperature and sleep rhythms in the rat," Physiology \& Behavior, vol. 32, no. 3, pp. 357-368, 1984.

[2] W. J. Schwartz and P. Zimmerman, "Lesions of the suprachiasmatic nucleus disrupt circadian locomotor rhythms in the mouse," Physiology \& Behavior, vol. 49, no. 6, pp. 1283-1287, 1991.

[3] C. H. Ko and J. S. Takahashi, "Molecular components of the mammalian circadian clock," Human Molecular Genetics, vol. 15, no. 2, pp. R271-R277, 2006.

[4] W. S. Warren, T. H. Champney, and V. M. Cassone, "The suprachiasmatic nucleus controls the circadian rhythm of heart rate via the sympathetic nervous system," Physiology \& Behavior, vol. 55, no. 6, pp. 1091-1099, 1994.

[5] A. Kalsbeek, S. La Fleur, C. Van Heijningen, and R. M. Buijs, "Suprachiasmatic GABAergic inputs to the paraventricular nucleus control plasma glucose concentrations in the rat via sympathetic innervation of the liver," The Journal of Neuroscience, vol. 24, no. 35, pp. 7604-7613, 2004.

[6] P. Pezük, J. A. Mohawk, L. A. Wang, and M. Menaker, "Glucocorticoids as entraining signals for peripheral circadian oscillators," Endocrinology, vol. 153, no. 10, pp. 4775-4783, 2012.

[7] A. Balsalobre, S. A. Brown, L. Marcacci et al., "Resetting of circadian time in peripheral tissues by glucocorticoid signaling," Science, vol. 289, no. 5488, pp. 2344-2347, 2000.

[8] J. Mendoza, “Circadian clocks: Setting time by food," Journal of Neuroendocrinology, vol. 19, no. 2, pp. 127-137, 2007.

[9] J. Mendoza, M. Angeles-Castellanos, and C. Escobar, "A daily palatable meal without food deprivation entrains the suprachiasmatic nucleus of rats," European Journal of Neuroscience, vol. 22, no. 11, pp. 2855-2862, 2005.

[10] H. Dardente and N. Cermakian, "Molecular circadian rhythms in central and peripheral clocks in mammals," Chronobiology International, vol. 24, no. 2, pp. 195-213, 2007.

[11] O. B. Sawant, A. M. Horton, O. F. Zucaro et al., "The Circadian Clock Gene Bmall Controls Thyroid Hormone-Mediated Spectral Identity and Cone Photoreceptor Function," Cell Reports, vol. 21, no. 3, pp. 692-706, 2017.

[12] S. Honma, T. Kawamoto, Y. Takagi et al., "Dec1 and Dec2 are regulators of the mammalian molecular clock," Nature, vol. 419, no. 6909, pp. 841-844, 2002.

[13] M. Stratmann, D. M. Suter, N. Molina, F. Naef, and U. Schibler, "Circadian Dbp Transcription Relies on Highly Dynamic BMAL1-CLOCK Interaction with E Boxes and Requires the Proteasome," Molecular Cell, vol. 48, no. 2, pp. 277-287, 2012. 
[14] S. Yamaguchi, S. Mitsui, L. Yan, K. Yagita, S. Miyake, and H. Okamura, "Role of DBP in the circadian oscillatory mechanism," Molecular and Cellular Biology, vol. 20, no. 13, pp. 47734781, 2000.

[15] B. J. Smith, G. M. Sutton, X. Wu et al., "Ovariectomy and genes encoding core circadian regulatory proteins in murine bone," Osteoporosis International, vol. 22, no. 5, pp. 1633-1639, 2011.

[16] Y. Tahara, Y. Takatsu, T. Shiraishi et al., "Age-related circadian disorganization caused by sympathetic dysfunction in peripheral clock regulation," npj Aging and Mechanisms of Disease, vol. 3, no. 1, 2017.

[17] C. Song, P. Tan, Z. Zhang et al., "REV-ERBs agonism suppresses osteoclastogenesis and prevents ovariectomy-induced bone loss partially," The FASEB Journal, vol. 32, no. 6, pp. 3215-3228, 2018.

[18] C. Swanson, S. A. Shea, P. Wolfe et al., "24-hour profile of serum sclerostin and its association with bone biomarkers in men," Osteoporosis International, vol. 28, no. 11, pp. 3205-3213, 2017.

[19] P. Qvist, S. Christgau, B. J. Pedersen, A. Schlemmer, and C. Christiansen, "Circadian variation in the serum concentration of C-terminal telopeptide of type I collagen (serum CTx): Effects of gender, age, menopausal status, posture, daylight, serum cortisol, and fasting," Bone, vol. 31, no. 1, pp. 57-61, 2002.

[20] G. G. Pellegrini, M. M. S. Gonzales Chaves, M. A. Fajardo et al., "Salivary bone turnover markers in healthy pre- and postmenopausal women: Daily and seasonal rhythm," Clinical Oral Investigations, vol. 16, no. 2, pp. 651-657, 2012.

[21] M. Kawai, S. Kinoshita, S. Shimba, K. Ozono, and T. Michigami, "Sympathetic activation induces skeletal Fgf23 expression in a circadian rhythm-dependent manner," The Journal of Biological Chemistry, vol. 289, no. 3, pp. 1457-1466, 2014.

[22] A. Dovio, D. Generali, M. Tampellini et al., "Variations along the 24-hour cycle of circulating osteoprotegerin and soluble RANKL: A rhythmometric analysis," Osteoporosis International, vol. 19, no. 1, pp. 113-117, 2008.

[23] M. Shimizu, Y. Onoe, M. Mikumo et al., "Variations in circulating osteoprotegerin and soluble RANKL during diurnal and menstrual cycles in young women," Hormone Research, vol. 71, no. 5, pp. 285-289, 2009.

[24] F. Joseph, B. Y. Chan, B. H. Durham et al., "The circadian rhythm of osteoprotegerin and its association with parathyroid hormone secretion," The Journal of Clinical Endocrinology \& Metabolism, vol. 92, no. 8, pp. 3230-3238, 2007.

[25] F. A. Al-Sobayil, "Circadian rhythm of bone formation biomarkers in serum of dromedary camels," Research in Veterinary Science, vol. 89, no. 3, pp. 455-459, 2010.

[26] J. Redmond, A. J. Fulford, L. Jarjou, B. Zhou, A. Prentice, and I. Schoenmakers, "Diurnal rhythms of bone turnover markers in three ethnic groups," The Journal of Clinical Endocrinology \& Metabolism, vol. 101, no. 8, pp. 3222-3230, 2016.

[27] J.-D. P. McElderry, G. Zhao, A. Khmaladze, C. G. Wilson, R. T. Franceschi, and M. D. Morris, "Tracking circadian rhythms of bone mineral deposition in murine calvarial organ cultures," Journal of Bone and Mineral Research, vol. 28, no. 8, pp. 18461854, 2013.

[28] J. E. Russell, B. Grazman, and D. J. Simmons, "Mineralization in Rat Metaphyseal Bone Exhibits a Circadian Stage Dependency," Proceedings of the Society for Experimental Biology and Medicine, vol. 176, no. 4, pp. 342-345, 1984.

[29] Y. Gafni, A. A. Ptitsyn, Y. Zilberman, G. Pelled, J. M. Gimble, and D. Gazit, "Circadian rhythm of osteocalcin in the maxillomandibular complex," Journal of Dental Research, vol. 88, no. 1, pp. 45-50, 2009.
[30] S. Zvonic, A. A. Ptitsyn, G. Kilroy et al., "Circadian oscillation of gene expression in murine calvarial bone," Journal of Bone and Mineral Research, vol. 22, no. 3, pp. 357-365, 2007.

[31] J. E. Russell, W. V. Walker, R. J. Fenster, and D. J. Simmons, "In Vitro Evaluation of Circadian Patterns of Bone Collagen Formation," Proceedings of the Society for Experimental Biology and Medicine, vol. 180, no. 2, pp. 375-381, 1985.

[32] J. M. Radziuk, “The suprachiasmatic nucleus, circadian clocks, and the liver," Diabetes, vol. 62, no. 4, pp. 1017-1019, 2013.

[33] S. M. Abbott, K. J. Reid, and P. C. Zee, "Circadian Rhythm SleepWake Disorders," Psychiatric Clinics of North America, vol. 38, no. 4, pp. 805-823, 2015.

[34] I. Quevedo and A. M. Zuniga, "Low bone mineral density in rotating-shift workers," Journal of Clinical Densitometry, vol. 13, no. 4, pp. 467-469, 2010.

[35] D. Feskanich, S. E. Hankinson, and E. S. Schernhammer, "Nightshift work and fracture risk: The Nurses' Health Study," Osteoporosis International, vol. 20, no. 4, pp. 537-542, 2009.

[36] A. Romano, L. Vigna, V. Belluigi et al., "Shift work and serum 25-OH vitamin D status among factory workers in Northern Italy: Cross-sectional study," Chronobiology International, vol. 32, no. 6, pp. 842-847, 2015.

[37] K. Wang, Y. Wu, Y. Yang et al., "The associations of bedtime, nocturnal, and daytime sleep duration with bone mineral density in pre- and post-menopausal women," Endocrine Journal, vol. 49, no. 2, pp. 538-548, 2015.

[38] C. M. Swanson, S. A. Shea, P. Wolfe et al., "Bone Turnover Markers After Sleep Restriction and Circadian Disruption: A Mechanism for Sleep-Related Bone Loss in Humans," The Journal of Clinical Endocrinology \& Metabolism, vol. 102, no. 10, pp. 3722-3730, 2017.

[39] T. S. Rogers, S. Harrison, C. Swanson et al., "Rest-activity circadian rhythms and bone mineral density in elderly men," Bone Reports, vol. 7, pp. 156-163, 2017.

[40] E. A. Lucassen, C. P. Coomans, M. van Putten et al., "Environmental 24-hr Cycles Are Essential for Health," Current Biology, vol. 26, no. 14, pp. 1843-1853, 2016.

[41] J. E. Russell, D. J. Simmons, B. Huber, and B. A. Roos, "Meal timing as a zeitgeber for skeletal deoxyribonucleic acid and collagen synthesis rhythms," Endocrinology, vol. 113, no. 6, pp. 2035-2042, 1983.

[42] R. C. Muhlbauer and H. Fleisch, "The diurnal rhythm of bone resorption in the rat. Effect of feeding habits and pharmacological inhibitors," The Journal of Clinical Investigation, vol. 95, no. 4, pp. 1933-1940, 1995.

[43] A. Schlemmer and C. Hassager, "Acute fasting diminishes the circadian rhythm of biochemical markers of bone resorption," European Journal of Endocrinology, vol. 140, no. 4, pp. 332-337, 1999.

[44] S. Lee, L. A. Donehower, A. J. Herron, D. D. Moore, and L. $\mathrm{Fu}$, "Disrupting circadian homeostasis of sympathetic signaling promotes tumor development in mice," PLoS ONE, vol. 5, no. 6, Article ID e10995, 2010.

[45] A. Ishida, T. Mutoh, T. Ueyama et al., "Light activates the adrenal gland: Timing of gene expression and glucocorticoid release," Cell Metabolism, vol. 2, no. 5, pp. 297-307, 2005.

[46] H. Terazono, T. Mutoh, S. Yamaguchi et al., "Adrenergic regulation of clock gene expression in mouse liver," Proceedings of the National Acadamy of Sciences of the United States of America, vol. 100, no. 11, pp. 6795-6800, 2003. 
[47] S. Chung, E. J. Lee, H. K. Cha et al., "Cooperative roles of the suprachiasmatic nucleus central clock and the adrenal clock in controlling circadian glucocorticoid rhythm," Scientific Reports, vol. 7, 2017.

[48] R. Y. Moore and V. B. Eichler, "Loss of a circadian adrenal corticosterone rhythm following suprachiasmatic lesions in the rat," Brain Research, vol. 42, no. 1, pp. 201-206, 1972.

[49] T. Yamamoto, Y. Nakahata, M. Tanaka et al., "Acute physical stress elevates mouse Periodl mRNA expression in mouse peripheral tissues via a glucocorticoid-responsive element," The Journal of Biological Chemistry, vol. 280, no. 51, pp. 4203642043, 2005.

[50] S. Komoto, H. Kondo, O. Fukuta, and A. Togari, "Comparison of $\beta$-adrenergic and glucocorticoid signaling on clock gene and osteoblast-related gene expressions in human osteoblast," Chronobiology International, vol. 29, no. 1, pp. 66-74, 2012.

[51] T. Hirai, K. Tanaka, and A. Togari, " $\beta$-adrenergic receptor signaling regulates Ptgs 2 by driving circadian gene expression in osteoblasts," Journal of Cell Science, vol. 127, no. 17, pp. 37113719, 2014.

[52] T. Hirai, K. Tanaka, and A. Togari, " $\alpha 1$-Adrenergic receptor signaling in osteoblasts regulates clock genes and bone morphogenetic protein 4 expression through up-regulation of the transcriptional factor nuclear factor IL-3 (Nfil3)/E4 promoterbinding protein 4 (E4BP4)," The Journal of Biological Chemistry, vol. 289, no. 24, pp. 17174-17183, 2014.

[53] Y.-C. Lee, C.-J. Cheng, M. A. Bilen et al., "BMP4 promotes prostate tumor growth in bone through osteogenesis," Cancer Research, vol. 71, no. 15, pp. 5194-5203, 2011.

[54] K. Tanaka, T. Hirai, D. Kodama, H. Kondo, K. Hamamura, and A. Togari, " $\alpha 1 \mathrm{~B}$-Adrenoceptor signalling regulates bone formation through the up-regulation of CCAAT/enhancerbinding protein delta expression in osteoblasts," British Journal of Pharmacology, vol. 173, no. 6, pp. 1058-1069, 2016.

[55] A. Kalsbeek, I. F. Palm, S. E. La Fleur et al., "SCN outputs and the hypothalamic balance of life," Journal of Biological Rhythms, vol. 21, no. 6, pp. 458-469, 2006.

[56] R. Dallmann, C. Touma, R. Palme, U. Albrecht, and S. Steinlechner, "Impaired daily glucocorticoid rhythm in Perl ${ }^{\text {Brd }}$ mice," Journal of Comparative Physiology A: Neuroethology, Sensory, Neural, and Behavioral Physiology, vol. 192, no. 7, pp. 769-775, 2006.

[57] S. Yang, A. Liu, A. Weidenhammer et al., "The role of mPer2 clock gene in glucocorticoid and feeding rhythms," Endocrinology, vol. 150, no. 5, pp. 2153-2160, 2009.

[58] X. Wu, G. Yu, H. Parks et al., "Circadian mechanisms in murine and human bone marrow mesenchymal stem cells following dexamethasone exposure," Bone, vol. 42, no. 5, pp. 861-870, 2008.

[59] N. Nader, G. P. Chrousos, and T. Kino, "Circadian rhythm transcription factor CLOCK regulates the transcriptional activity of the glucocorticoid receptor by acetylating its hinge region lysine cluster: potential physiological implications," The FASEB Journal, vol. 23, no. 5, pp. 1572-1583, 2009.

[60] A. Rauch, S. Seitz, U. Baschant et al., "Glucocorticoids suppress bone formation by attenuating osteoblast differentiation via the monomeric glucocorticoid receptor," Cell Metabolism, vol. 11, no. 6, pp. 517-531, 2010.

[61] Y. Fujihara, H. Kondo, T. Noguchi, and A. Togari, "Glucocorticoids mediate circadian timing in peripheral osteoclasts resulting in the circadian expression rhythm of osteoclastrelated genes," Bone, vol. 61, pp. 1-9, 2014.
[62] E. E. Benarroch, "Suprachiasmatic nucleus and melatonin: Reciprocal interactions and clinical correlations," Neurology, vol. 71, no. 8, pp. 594-598, 2008.

[63] S. R. Pandi-Perumal, V. Srinivasan, G. J. M. Maestroni, D. P. Cardinali, B. Poeggeler, and R. Hardeland, "Melatonin: nature's most versatile biological signal?” FEBS Journal, vol. 273, no. 13, pp. 2813-2838, 2006.

[64] L. Zhang, P. Su, C. Xu et al., "Melatonin inhibits adipogenesis and enhances osteogenesis of human mesenchymal stem cells by suppressing PPAR $\gamma$ expression and enhancing Runx 2 expression," Journal of Pineal Research, vol. 49, no. 4, pp. 364-372, 2010.

[65] K.-H. Park, J. W. Kang, E.-M. Lee et al., "Melatonin promotes osteoblastic differentiation through the BMP/ERK/Wnt signaling pathways," Journal of Pineal Research, vol. 51, no. 2, pp. 187194, 2011.

[66] H. Koyama, O. Nakade, Y. Takada, T. Kaku, and K.-H. W. Lau, "Melatonin at pharmacologic doses increases bone mass by suppressing resorption through down-regulation of the RANKL-mediated osteoclast formation and activation," Journal of Bone and Mineral Research, vol. 17, no. 7, pp. 1219-1229, 2002.

[67] P. A. Witt-Enderby, J. P. Slater, N. A. Johnson et al., "Effects on bone by the light/dark cycle and chronic treatment with melatonin and/or hormone replacement therapy in intact female mice," Journal of Pineal Research, vol. 53, no. 4, pp. 374-384, 2012.

[68] M. P. Kotlarczyk, H. C. Lassila, C. K. O’Neil et al., "Melatonin osteoporosis prevention study (MOPS): A randomized, doubleblind, placebo-controlled study examining the effects of melatonin on bone health and quality of life in perimenopausal women," Journal of Pineal Research, vol. 52, no. 4, pp. 414-426, 2012.

[69] P. C. Yannielli, P. C. Molyneux, M. E. Harrington, and D. A. Golombek, "Ghrelin effects on the circadian system of mice," The Journal of Neuroscience, vol. 27, no. 11, pp. 2890-2895, 2007.

[70] E. W. Lamont, J. Bruton, I. D. Blum, and A. Abizaid, "Ghrelin receptor-knockout mice display alterations in circadian rhythms of activity and feeding under constant lighting conditions," European Journal of Neuroscience, vol. 39, no. 2, pp. 207217, 2014.

[71] K. W. Oh, W. Y. Lee, E. J. Rhee et al., “The relationship between serum resistin, leptin, adiponectin, ghrelin levels and bone mineral density in middle-aged men," Clinical Endocrinology, vol. 63, no. 2, pp. 131-138, 2005.

[72] L. A. Weiss, E. Barrett-Connor, D. Von Mühlen, and P. Clark, "Leptin predicts BMD and bone resorption in older women but not older men: The Rancho Bernardo Study, Journal of Bone and Mineral Research, vol. 21, no. 5, pp. 758-764, 2006.

[73] W. D. Fraser, A. M. Ahmad, and J. P. Vora, "The physiology of the circadian rhythm of parathyroid hormone and its potential as a treatment for osteoporosis," Current Opinion in Nephrology and Hypertension, vol. 13, no. 4, pp. 437-444, 2004.

[74] R. Hanyu, T. Hayata, M. Nagao et al., "Per-1 is a specific clock gene regulated by parathyroid hormone (PTH) signaling in osteoblasts and is functional for the transcriptional events induced by PTH," Journal of Cellular Biochemistry, vol. 112, no. 2, pp. 433-438, 2011.

[75] N. Okubo, H. Fujiwara, Y. Minami et al., "Parathyroid hormone resets the cartilage circadian clock of the organ-cultured murine femur," Acta Orthopaedica, vol. 86, no. 5, pp. 627-631, 2015.

[76] T. Kunimoto, N. Okubo, Y. Minami et al., "A PTH-responsive circadian clock operates in ex vivo mouse femur fracture healing site," Scientific Reports, vol. 6, 2016. 
[77] R. Zhang, N. F. Lahens, H. I. Ballance, M. E. Hughes, and J. B. Hogenesch, "A circadian gene expression atlas in mammals: implications for biology and medicine," Proceedings of the National Acadamy of Sciences of the United States of America, vol. 111, no. 45, pp. 16219-16224, 2014.

[78] L. Yan, "Expression of clock genes in the suprachiasmatic nucleus: Effect of environmental lighting conditions," Reviews in Endocrine and Metabolic Disorders, vol. 10, no. 4, pp. 301-310, 2009.

[79] H. Boucher, V. Vanneaux, T. Domet, A. Parouchev, and J. Larghero, "Circadian clock genes modulate human bone marrow mesenchymal stem cell differentiation, migration and cell cycle," PLoS ONE, vol. 11, no. 1, 2016.

[80] M. H. Vitaterna, D. P. King, A.-M. Chang et al., "Mutagenesis and mapping of a mouse gene, clock, essential for circadian behavior," Science, vol. 264, no. 5159, pp. 719-725, 1994.

[81] J. P. DeBruyne, E. Noton, C. M. Lambert, E. S. Maywood, D. R. Weaver, and S. M. Reppert, "A clock shock: mouse CLOCK is not required for circadian oscillator function," Neuron, vol. 50, no. 3, pp. 465-477, 2006.

[82] J. P. DeBruyne, D. R. Weaver, and S. M. Reppert, "CLOCK and NPAS2 have overlapping roles in the suprachiasmatic circadian clock," Nature Neuroscience, vol. 10, no. 5, pp. 543-545, 2007.

[83] G. Yuan, B. Hua, Y. Yang et al., "The Circadian Gene Clock Regulates Bone Formation Via PDIA3," Journal of Bone and Mineral Research, vol. 32, no. 4, pp. 861-871, 2017.

[84] Y. Wang, A. Nizkorodov, K. Riemenschneider et al., "Impaired bone formation in pdia3 deficient mice," PLoS ONE, vol. 9, no. 11, 2014.

[85] M. K. Bunger, L. D. Wilsbacher, S. M. Moran et al., "Mop3 is an essential component of the master circadian pacemaker in mammals," Cell, vol. 103, no. 7, pp. 1009-1017, 2000.

[86] R. V. Kondratov, A. A. Kondratova, V. Y. Gorbacheva, O. V. Vykhovanets, and M. P. Antoch, "Early aging and age-related pathologies in mice deficient in BMAL1, the core component of the circadian clock," Genes \& Development, vol. 20, no. 14, pp. 1868-1873, 2006.

[87] W. E. Samsa, A. Vasanji, R. J. Midura, and R. V. Kondratov, "Deficiency of circadian clock protein BMAL1 in mice results in a low bone mass phenotype," Bone, vol. 84, pp. 194-203, 2016.

[88] T. Takarada, C. Xu, H. Ochi et al., "Bone Resorption Is Regulated by Circadian Clock in Osteoblasts," Journal of Bone and Mineral Research, vol. 32, no. 4, pp. 872-881, 2017.

[89] K. Bae, X. Jin, E. S. Maywood, M. H. Hastings, S. M. Reppert, and D. R. Weaver, "Differential functions of $m$ Perl, $m$ Per2, and $m P e r 3$ in the SCN circadian clock," Neuron, vol. 30, no. 2, pp. 525-536, 2001.

[90] L. P. Shearman, M. J. Zylka, D. R. Weaver, L. F. Kolakowski Jr., and S. M. Reppert, "Two period homologs: Circadian expression and photic regulation in the suprachiasmatic nuclei," Neuron, vol. 19, no. 6, pp. 1261-1269, 1997.

[91] L. Fu, M. S. Patel, A. Bradley, E. F. Wagner, and G. Karsenty, “The molecular clock mediates leptin-regulated bone formation," Cell, vol. 122, no. 5, pp. 803-815, 2005.

[92] E. Maronde, A. F. Schilling, S. Seitz et al., "The clock genes Period 2 and Cryptochrome 2 differentially balance bone formation," PLoS ONE, vol. 5, no. 7, 2010.

[93] M. H. Vitaterna, C. P. Selby, T. Todo et al., "Differential regulation of mammalian period genes and circadian rhythmicity by cryptochromes 1 and 2," Proceedings of the National Acadamy of Sciences of the United States of America, vol. 96, no. 21, pp. 12114-12119, 1999.
[94] B. Zheng, U. Albrecht, K. Kaasik et al., "Nonredundant roles of the mPerl and mPer2 genes in the mammalian circadian clock," Cell, vol. 105, no. 5, pp. 683-694, 2001.

[95] R. J. Thresher, M. H. Vitaterna, Y. Miyamoto et al., "Role of mouse cryptochrome blue-light photoreceptor in circadian photoresponses," Science, vol. 282, no. 5393, pp. 1490-1494, 1998.

[96] Y. Li, J. Zhou, Y. Wu et al., "Association of osteoporosis with genetic variants of circadian genes in Chinese geriatrics," Osteoporosis International, vol. 27, no. 4, pp. 1485-1492, 2016.

[97] A. Bugge, D. Feng, L. J. Everett et al., "Rev-erb $\alpha$ and Rev-erb $\beta$ coordinately protect the circadian clock and normal metabolic function," Genes \& Development, vol. 26, no. 7, pp. 657-667, 2012.

[98] E. Woldt, Y. Sebti, L. A. Solt et al., "Rev-erb- $\alpha$ modulates skeletal muscle oxidative capacity by regulating mitochondrial biogenesis and autophagy," Nature Medicine, vol. 19, no. 8, pp. 1039-1046, 2013.

[99] J. M. Yu, X. Wu, J. M. Gimble, X. Guan, M. A. Freitas, and B. A. Bunnell, "Age-related changes in mesenchymal stem cells derived from rhesus macaque bone marrow," Aging Cell, vol. 10, no. 1, pp. 66-79, 2011.

[100] Y. He, F. Lin, Y. Chen, Z. Tan, D. Bai, and Q. Zhao, “Overexpression of the circadian clock gene rev-erb $\alpha$ affects murine bone mesenchymal stem cell proliferation and osteogenesis," Stem Cells and Development, vol. 24, no. 10, pp. 1194-1204, 2015.

[101] A. Medvedev, Z.-H. Yan, T. Hirose, V. Giguère, and A. M. Jetten, "Cloning of a cDNA encoding the murine orphan receptor RZR/ROR $\gamma$ and characterization of its response element," Gene, vol. 181, no. 1-2, pp. 199-206, 1996.

[102] M. Akashi and T. Takumi, "The orphan nuclear receptor ROR $\alpha$ regulates circadian transcription of the mammalian core-clock Bmall," Nature Structural \& Molecular Biology, vol. 12, no. 5, pp. 441-448, 2005.

[103] M. I. Masana, I. C. Sumaya, M. Becker-Andre, and M. L. Dubocovich, "Behavioral characterization and modulation of circadian rhythms by light and melatonin in $\mathrm{C} 3 \mathrm{H} / \mathrm{HeN}$ mice homozygous for the ROR $\beta$ knockout," American Journal of Physiology-Regulatory, Integrative and Comparative Physiology, vol. 292, no. 6, pp. R2357-R2367, 2007.

[104] T. Meyer, M. Kneissel, J. Mariani, and B. Fournier, "In vitro and in vivo evidence for orphan nuclear receptor RORalpha function in bone metabolism," Proceedings of the National Acadamy of Sciences of the United States of America, vol. 97, no. 16, pp. 9197-9202, 2000.

[105] J. A. R. Gordon, C. E. Tye, A. V. Sampaio, T. M. Underhill, G. K. Hunter, and H. A. Goldberg, "Bone sialoprotein expression enhances osteoblast differentiation and matrix mineralization in vitro," Bone, vol. 41, no. 3, pp. 462-473, 2007.

[106] M. M. Roforth, S. Khosla, and D. G. Monroe, "Identification of Ror $\beta$ targets in cultured osteoblasts and in human bone," Biochemical and Biophysical Research Communications, vol. 440, no. 4, pp. 768-773, 2013.

[107] M. M. Roforth, G. Liu, S. Khosla, and D. G. Monroe, "Examination of nuclear receptor expression in osteoblasts reveals ror $\beta$ as an important regulator of osteogenesis," Journal of Bone and Mineral Research, vol. 27, no. 4, pp. 891-901, 2012.

[108] J. N. Farr, M. M. Weivoda, K. M. Nicks et al., "Osteoprotection Through the Deletion of the Transcription Factor Ror $\beta$ in Mice," Journal of Bone and Mineral Research, vol. 33, no. 4, pp. 720-731, 2018.

[109] A. Nakashima, T. Kawamoto, K. K. Honda et al., "DEC1 modulates the circadian phase of clock gene expression," Molecular and Cellular Biology, vol. 28, no. 12, pp. 4080-4092, 2008. 
[110] Y. He, C. R. Jones, N. Fujiki et al., "The transcriptional repressor DEC2 regulates sleep length in mammals," Science, vol. 325, no. 5942, pp. 866-870, 2009.

[111] T. Iwata, T. Kawamoto, E. Sasabe et al., "Effects of overexpression of basic helix-loop-helix transcription factor Decl on osteogenic and adipogenic differentiation of mesenchymal stem cells," European Journal of Cell Biology, vol. 85, no. 5, pp. 423431, 2006

[112] M. Shen, E. Yoshida, W. Yan et al., "Basic helix-loop-helix protein DEC1 promotes chondrocyte differentiation at the early and terminal stages," The Journal of Biological Chemistry, vol. 277, no. 51, pp. 50112-50120, 2002.

[113] D. D. Bikle, E. Gee, B. Halloran, M. A. Kowalski, E. Ryzen, and J. G. Haddad, "Assessment of the free fraction of 25hydroxyvitamin $\mathrm{d}$ in serum and its regulation by albumin and the vitamin d-binding protein," The Journal of Clinical Endocrinology \& Metabolism, vol. 63, no. 4, pp. 954-959, 1986.

[114] G. B. Schneider, K. A. Benis, N. W. Flay, R. A. Ireland, and S. N. Popoff, "Effects of vitamin D binding protein-macrophage activating factor (DBP-MAF) infusion on bone resorption in two osteopetrotic mutations," Bone, vol. 16, no. 6, pp. 657-662, 1995.

[115] P. Fonjallaz, V. Ossipow, G. Wanner, and U. Schibler, “The two PAR leucine zipper proteins, TEF and DBP, display similar circadian and tissue-specific expression, but have different target promoter preferences," EMBO Journal, vol. 15, no. 2, pp. 351-362, 1996.

[116] M. Pekkinen, E. Saarnio, H. T. Viljakainen et al., "Vitamin $\mathrm{D}$ binding protein genotype is associated with serum 25hydroxyvitamin D and PTH concentrations, as well as bone health in children and adolescents in Finland," PLOS ONE, vol. 9, no. 1, 2014.

[117] R. I. Khusainova, L. I. Seleznyova, A. V. Mal'Tsev et al., "Associations between vitamin D-binding protein (DBP) gene polymorphism (TAAA)nand development of osteoporosis in the Volga-Ural Region of Russia," Bulletin of Experimental Biology and Medicine, vol. 157, no. 2, pp. 253-257, 2014.

[118] Z. H. Al-Oanzi, S. P. Tuck, S. S. Mastana et al., "Vitamin Dbinding protein gene microsatellite polymorphism influences BMD and risk of fractures in men," Osteoporosis International, vol. 19, no. 7, pp. 951-960, 2008.

[119] D.-H. Xiong, H. Shen, L.-J. Zhao et al., "Robust and comprehensive analysis of 20 osteoporosis candidate genes by very high-density single-nucleotide polymorphism screen among 405 white nuclear families identified significant association and gene-gene interaction," Journal of Bone and Mineral Research, vol. 21, no. 11, pp. 1678-1695, 2006.

[120] F. F. Safadi, P. Thornton, H. Magiera et al., "Osteopathy and resistance to vitamin $\mathrm{D}$ toxicity in mice null for vitamin $\mathrm{D}$ binding protein," The Journal of Clinical Investigation, vol. 103, no. 2, pp. 239-251, 1999.

[121] Y. Yamanaka, Y. Suzuki, T. Todo, K.-I. Honma, and S. Honma, "Loss of circadian rhythm and light-induced suppression of pineal melatonin levels in Cryl and Cry2 double-deficient mice," Genes to Cells, vol. 15, no. 10, pp. 1063-1071, 2010.

[122] N. Preitner, F. Damiola, L. Lopez-Molina et al., "The orphan nuclear receptor REV-ERB $\alpha$ controls circadian transcription within the positive limb of the mammalian circadian oscillator," Cell, vol. 110, no. 2, pp. 251-260, 2002.

[123] H. Cho, X. Zhao, M. Hatori et al., "Regulation of circadian behaviour and metabolism by REV-ERB- $\alpha$ and REV-ERB- $\beta$," Nature, vol. 485, no. 7396, pp. 123-127, 2012.
[124] L. Lopez-Molina, F. Conquet, M. Dubois-Dauphin, and U. Schibler, "The DBP gene is expressed according to a circadian rhythm in the suprachiasmatic nucleus and influences circadian behavior," EMBO Journal, vol. 16, no. 22, pp. 6762-6771, 1997.

[125] M. A. Karsdal, I. Byrjalsen, B. J. Riis, and C. Christiansen, "Investigation of the diurnal variation in bone resorption for optimal drug delivery and efficacy in osteoporosis with oral calcitonin," BMC Clinical Pharmacology, vol. 8, 2008.

[126] D. Michalska, M. Luchavova, V. Zikan, I. Raska Jr., A. A. Kubena, and J. J. Stepan, "Effects of morning vs. evening teriparatide injection on bone mineral density and bone turnover markers in postmenopausal osteoporosis," Osteoporosis International, vol. 23, no. 12, pp. 2885-2891, 2012.

[127] D. Jing, G. Shen, J. Huang et al., "Circadian rhythm affects the preventive role of pulsed electromagnetic fields on ovariectomy-induced osteoporosis in rats," Bone, vol. 46, no. 2, pp. 487-495, 2010.

[128] N. C. Wright, A. C. Looker, K. G. Saag et al., "The recent prevalence of osteoporosis and low bone mass in the United States based on bone mineral density at the femoral neck or lumbar," Journal of Bone and Mineral Research, 2014.

[129] S. W. Blume and J. R. Curtis, "Medical costs of osteoporosis in the elderly Medicare population," Osteoporosis International, vol. 22, no. 6, pp. 1835-1844, 2011.

[130] E. S. Musiek, "Circadian clock disruption in neurodegenerative diseases: cause and effect?" Frontiers in Pharmacology, vol. 6, 2015.

[131] N. N. Guerrero-Vargas, R. Navarro-Espíndola, M. A. GuzmánRuíz et al., "Circadian disruption promotes tumor growth by anabolic host metabolism; experimental evidence in a rat model," BMC Cancer, vol. 17, no. 1, 2017.

[132] L. Chen and G. Yang, "Recent advances in circadian rhythms in cardiovascular system," Frontiers in Pharmacology, vol. 6, article 71, 2015.

[133] Y. Wang, N. Kumar, L. A. Solt et al., "Modulation of retinoic acid receptor-related orphan receptor $\alpha$ and $\gamma$ activity by 7oxygenated sterol ligands," The Journal of Biological Chemistry, vol. 285, no. 7, pp. 5013-5025, 2010.

[134] G. Sulli, A. Rommel, X. Wang et al., "Pharmacological activation of REV-ERBs is lethal in cancer and oncogene-induced senescence," Nature, vol. 553, no. 7688, pp. 351-355, 2018.

[135] L. A. Solt, S. Banerjee, S. Campbell, T. M. Kamenecka, and T. P. Burris, "ROR inverse agonist suppresses insulitis and prevents hyperglycemia in a mouse model of type 1 diabetes," Endocrinology, vol. 156, no. 3, pp. 869-881, 2015.

[136] S. Sitaula, C. Billon, T. M. Kamenecka, L. A. Solt, and T. P. Burris, "Suppression of atherosclerosis by synthetic REV-ERB agonist," Biochemical and Biophysical Research Communications, vol. 460, no. 3, pp. 566-571, 2015.

[137] Y. Wang, C. Billon, J. K. Walker, and T. P. Burris, “Therapeutic effect of a synthetic RORalpha/gamma agonist in an animal model of autism," ACS Chemical Neuroscience, vol. 7, no. 2, pp. 143-148, 2016.

[138] D. J. Kojetin and T. P. Burris, "REV-ERB and ROR nuclear receptors as drug targets," Nature Reviews Drug Discovery, vol. 13, no. 3, pp. 197-216, 2014. 


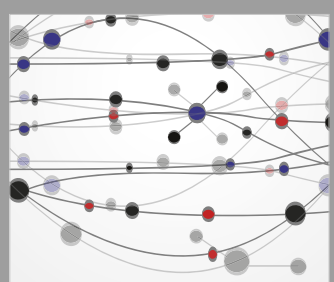

The Scientific World Journal
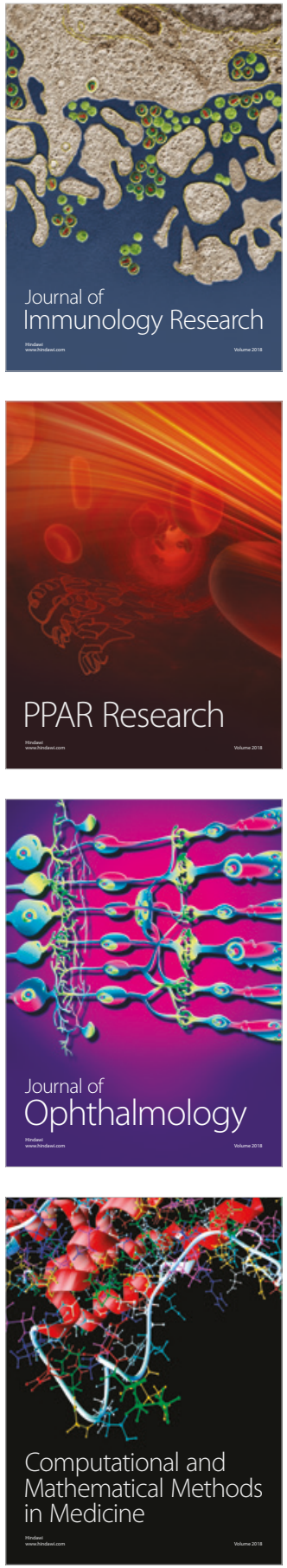

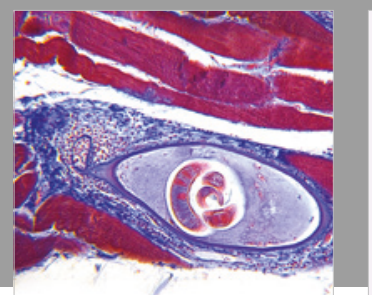

Gastroenterology Research and Practice

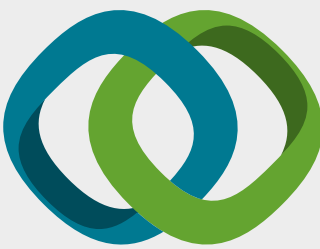

\section{Hindawi}

Submit your manuscripts at

www.hindawi.com
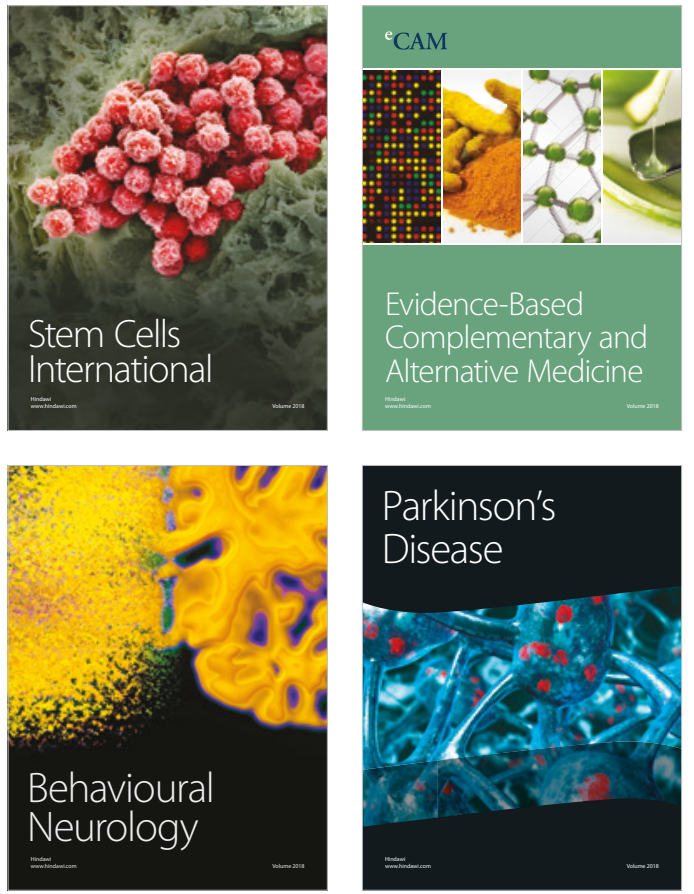

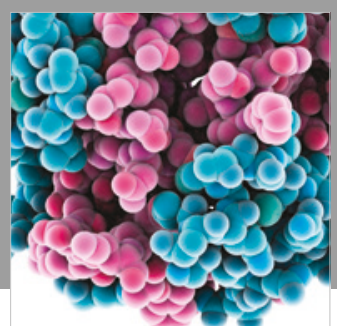

ournal of

Diabetes Research

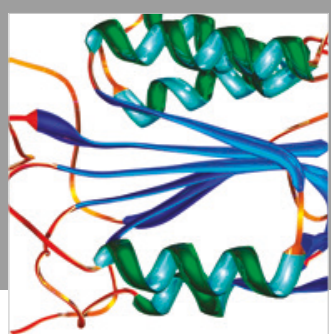

Disease Markers
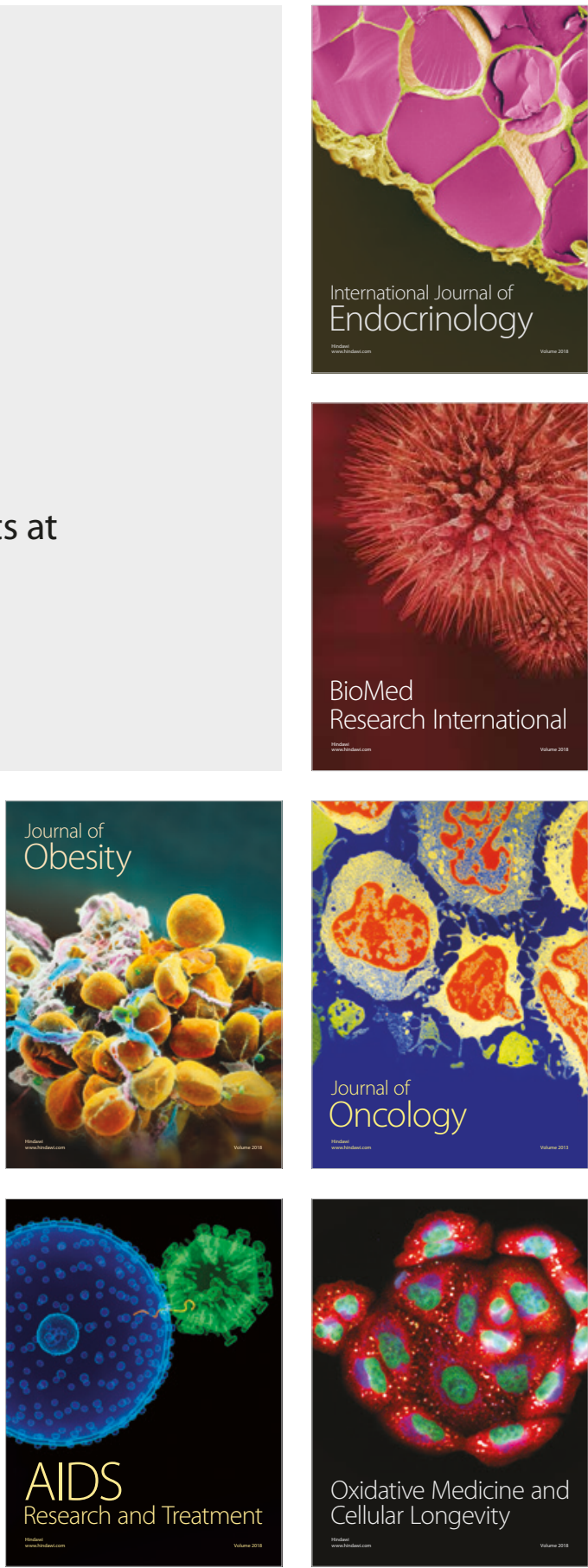